\title{
ASSESSMENT OF LEVELS OF OCCUPATIONAL EXPOSURE TO EXTREMELY LOW FREQUENCY ELECTRIC AND MAGNETIC FIELDS IN A DATA CENTRE IN GREATER ACCRA REGION - GHANA
}

\author{
J. Kalognia*, J. J. Fletcher, J. Amoako And A. Sawyerr \\ (J. $K \&$ A.S.: CSIR - Institute of Scientific and Technology Information, \\ Ghana; J. J. F.: University for Development Studies, Navrongo, Ghana; J. A.: Radiation Pro- \\ tection Institute, Ghana Atomic Energy Commission, Ghana). \\ *Corresponding author's email: jkalognia@st.ug.edu.gh
}

\begin{abstract}
The Electric and Magnetic fields for workers in a data centre in the Greater Accra Region was assessed. The fundamental objective was to determine the levels of the electric and magnetic fields and to assess the extent of exposure of workers in the data centre to these fields. The results for the electric field intensities in the data centre ranged from $6.03 \mathrm{E}-03 \pm 7.54 \mathrm{E}-04 \mathrm{kVm}-{ }^{1}$ to $2.33 \mathrm{E}-04 \pm 8.82 \mathrm{E}-05 \mathrm{kVm}^{-}{ }^{-}$. The results obtained for the magnetic flux density ranged from $3.9 \mathrm{E}-$ $07 \pm 8.77 \mathrm{E}-03 \mu \mathrm{T}$ to $7.27 \mathrm{E}-08 \pm 7.31 \mathrm{E}-03 \mu \mathrm{T}$. The results obtained for the induced current density ranged from $2.37 \mathrm{E}-06 \pm 1.50 \mathrm{E}-02 \mathrm{~mA} / \mathrm{m}^{2}$ to $2.46 \mathrm{E}-07 \pm 9.99 \mathrm{E}-03 \mathrm{~mA} / \mathrm{m}^{2}$. Data obtained were below the basic restrictions for induced current density and reference levels for electric field and magnetic flux density set by the International Commission on Non-Ionizing Radiation Protection.
\end{abstract}

\section{Introduction}

Non-ionizing radiation (NIR) refers to any type of electromagnetic radiation that does not cause ionization (remove electrons from atoms) but may have enough energy to cause excitation of atoms and molecules. NIR encompasses the long wavelength $(>10 \mathrm{~nm})$, low photon energy $(<12.4 \mathrm{eV})$ portion of the electromagnetic spectrum from $1 \mathrm{~Hz}$ to $3 \mathrm{x}$ $1015 \mathrm{~Hz}$. NIR cannot be perceived by any human senses unless its intensity is so great that it is felt as heat. Narrow visible region is an exception. The ability to penetrate the human body, the sites of absorption and the subsequent health effects are very much frequency dependent (Kwan-Hoong, 2003).Data centres are facilities used to house computer systems and associated components such as storage and telecommunication systems. The equipment in the data centres are often in a form of servers mounted in 19 inch (0.4826 meters) rack cabinet. Data centres are used to run IT systems applications that handle the core business and operational data of an organization and also for off-site backups. Data centres use a lot of power, consumed by two main usages: power required to run the actual equipment and power required to cool the equipment (Glanz, 2012). Usage of electricity results in the production of electric and magnetic fields (EMF). There are two types of EMF, classified according to the frequency range: extremely low frequency (ELF) fields and very low frequency (VLF) 
fields. These frequency fields are non-ionizing. ELF fields are defined by frequency range of 3 - $30 \mathrm{kHz}$. Electric and magnetic fields act independently of one another and are measured separately because of the quasi-static nature of the electromagnetic (EM) fields at these frequencies. Electric fields produced by voltage and measured in volts per meter $(\mathrm{V} / \mathrm{m})$ are present when an electric appliance is plugged in. The appliance does not need to be turned on for electric fields to be detected. Magnetic fields which are induced by alternating current (AC) and measured using derived quantity magnetic flux density (B) in Tesla (T) or Gauss (G) are present when the appliance is turned on.

EMF strength decrease as we move away from their source. EMF exposure is found in and around our homes and offices (Habash, 2001). Above the ELF range, electromagnetic fields propagate by means of tightly coupled electric and magnetic fields (radiation). In such cases, the magnitude of the electric field can be calculated exactly if the magnetic field is known and vice versa. However in the ELF range, the electric and magnetic fields are effectively uncoupled and can be evaluated separately as if they rose from independent sources.

At the low frequencies where it is customary to use the quasi-static approximation, the wavelength of electric and magnetic fields are very large (approximately $5000 \mathrm{~km}$ at $60 \mathrm{~Hz}$ ) in relation to the size and distances of objects of interest (NRPB, 2001).

Electric and magnetic fields can occur together or separately. Therefore it is possible for humans to be exposed to just one of these fields or both. The electricity used is alternating current (AC), meaning electric charges oscillate at a particular frequency. Frequency of oscillation in Ghana is $50 \mathrm{~Hz}$. The earth's static fields are similar to the fields generated by direct current (DC) electricity. Because these fields are stat- ic rather than alternating, they do not induce currents in stationary objects as do fields associated with alternating current. Such static fields can induce currents in rotating and moving objects. Even though electricity is useful in human lives, there have been reported cases of adverse health effects from EMF generated from its use (ICNIRP, 1998).

Because electricity is used all-over the world and plays a vital role in society's economy, the possibility of harm from EMF to electric utility customers and workers deserves attention. This study's primary objective was to determine the level of exposure of workers to Electromagnetic Fields in data centres. This was achieved through the following tasks:

- Measurement of the intensities of electric and magnetic fields inside the data centre.

- Determination of the Resultant Field Strength

- Determination of the Induced Current Density inside the body.

- Determination of the Magnetic Flux Density in the body.

- Comparison of the Electric and Magnetic field levels with internationally recommended standards such as ICNIRP and WHO.

\section{Experimental}

\section{Measuring Instruments}

The instrument used to measure the electric and magnetic fields is the ME 3851A Digital Electrostress Analyzer with F1B2H31 (frequency filter module: $16 \mathrm{~Hz}$ Band Pass $/ 50 \mathrm{~Hz}$ High Pass/ 2 kHz High Pass) made in Germany by Gigahertz solutions. 
Measuring AC Electric fields

In order to obtain reliable and reproducible results, the field meter was connected to a ground potential through the supplied grounding lead or grounding clip. The jack plug of the grounding lead was inserted into the dedicated socket (ground icon) with the grounding lead running alongside the case to the back. The AC or DC socket was touched with the finger in order to bring the body to the ground potential.

\section{Positioning of the Field meter}

The field meter has been calibrated for measurements taken in close proximity to the body. Field sources located behind the field meter are shielded through the body in order to avoid misleading concentrations of field lines onto the electric field sensor. Stretch-out arm measurements were avoided.

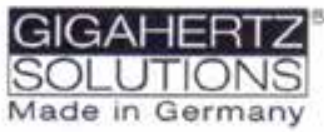

\title{
CERTIFICATE OF CALIBRATION
}

\author{
Gigahertz Solutions $\mathrm{GmbH}$ hereby \\ certifies that this instrument for measuring \\ alternating fields was calibrated during the \\ manufacturing process.
}

Gigahertz Solutions $\mathrm{GmbH}$ further certifies that the laboratory instrumentation used to prove this instrument's quality have been calibrated to a laboratory standard directly traceable to the German "Physikalisch-Technische Bundesanstalt", the National Institute of Standards, or natural physical constants at planned intervals.

Gigahertz Solutions" "Total Quality" System is monitored by VDE, the German Association for Electrical, Electronic \& Information Technologies to assure the compliance of the manufactured products to published specifications, especially for the safety of the produced demand switches.

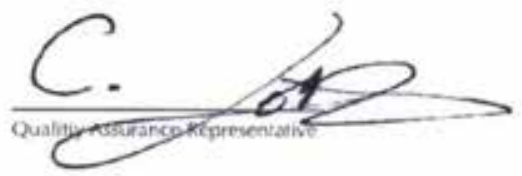

Gigahertz Solutions GmbH. Am Galgenberg 12. 90579 Langenzenn, Germany

Fig. 1: Certificate of Calibration. 


\section{AC Electric Field Testing}

The field meter was turned on and the switch "Field Type" is set to "E" foe AC electric field The frequency filter was set to " $5 \mathrm{~Hz}$ to 100 $\mathrm{kHz}$ ". The grounding lead must run to the back of the case and the person performing the survey as well as anybody around must be located behind the field meter. The field meter was held close to the body. Further away will give a false or higher reading.

\section{AC Magnetic Field Testing}

The field meter was turned on and the switch "Field Type" was set to " $\mathrm{M}$ " for AC magnetic field. The frequency filter was set to " $5 \mathrm{~Hz}$ to $100 \mathrm{kHz}$ ". For reliable measurements of AC magnetic fields, neither the field meter nor the person performing the measurements was grounded. The resultant, total magnetic field strength (the sum of the single field strengths,
3-D measurement) can be accurately calculated according to the following equation:

Resultant field strength $=$ Square Root

$$
\left(\mathrm{X}^{2}+\mathrm{Y}^{2}+\mathrm{Z}^{2}\right)
$$

A tape measure was used to measure the various heights and distances.

\section{Description of Site and Measurement \\ Procedures.}

Measurements were taken at Tigo data centre in Ghana. The data centre is located at Barnes Road, adjacent Data Bank, opposite National Service Secretariat building in Accra. The area of the data center room was $67.633 \mathrm{~m} 2$. The room contains about four hundred (400) servers: four (4) rack rows and seven (7) racks on each row and five (5) air conditioning units.

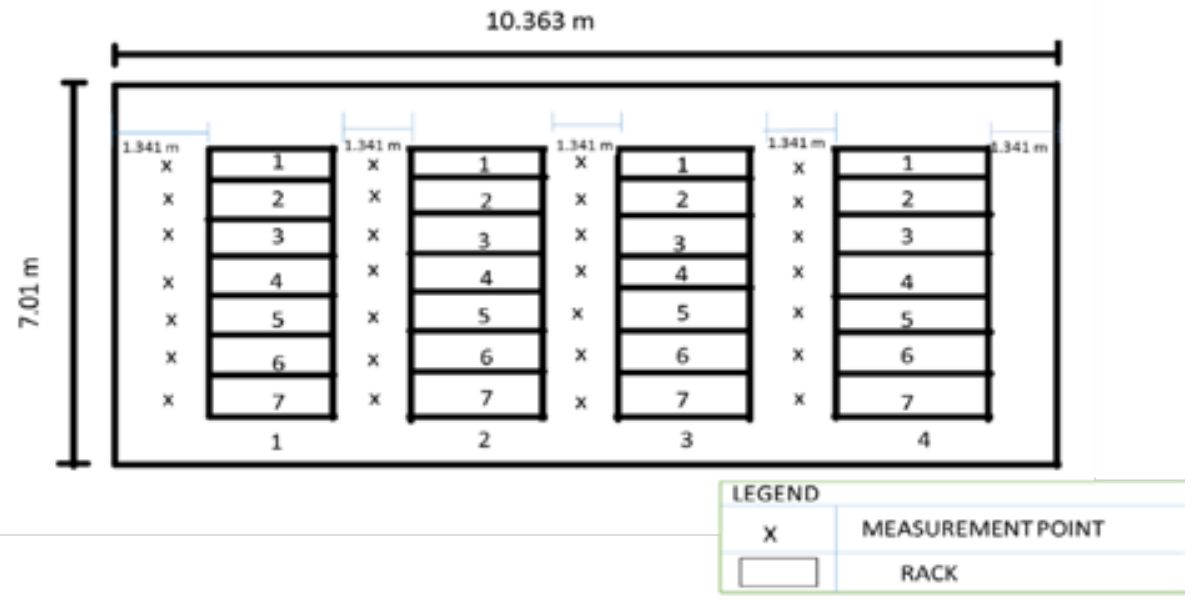

Fig. 1: Sketch of Data Centre

Measurements of electric and magnetic fields were taken in front of each rack. For the electric field the instrument was grounded before reading was recorded. This was done in different heights of $0.6 \mathrm{~m}, 1.0 \mathrm{~m}, 1.5 \mathrm{~m}, 1.6 \mathrm{~m}$ and
$1.7 \mathrm{~m}$ and a distance of $0.671 \mathrm{~m}$ from every rack. Since the distance between one rack and the wall or one rack and a rack in front of it was $1.341 \mathrm{~m}, 0.671 \mathrm{~m}$ was the best distance one can stand when working on a server in a rack. The 
same procedure was done for the magnetic field measurements but the equipment was not grounded. Magnetic field measurement in the $\mathrm{x}, \mathrm{y}$ and $\mathrm{z}$ axis were taken in front of each rack.

\section{Data analysis}

\section{Calculation of Induced Current Densities due to ELF MFs}

The current density induced in a circular shaped conductive object, by a uniform magnetic field derived from the Faraday's law of induction, is given by

$$
J=\sigma . \pi . \text {.r. f .B }
$$

Where

$\mathrm{J}=$ the current density $\left(\mathrm{A} / \mathrm{m}^{2}\right)$;

$\sigma=$ the conductivity of the medium taken as

$0.2 \mathrm{~S} / \mathrm{m}$;

$\pi=3.14$

$\mathrm{r}=$ the radius of the object $(\mathrm{m})$;

$\mathrm{f}=$ the frequency of the magnetic field, $50 \mathrm{~Hz}$

in this case;

$B=$ the magnetic flux density $(\mu T)$.

Current density can be defined as the amount of current flowing through a given cross sectional area in a given time interval. The exposure limit field for uniform fields (in the frequency range $1 \mathrm{~Hz}$ to $1 \mathrm{kHz}$ ) is an induced current density in the central nervous system of 10 $\mathrm{mA} / \mathrm{m}^{2}$ and is in accordance with ICNIRP. The standard further notes that the uniform electric (unperturbed) and magnetic fields correspond to the exposure limit value calculations carried out by previous studies for detailed anatomical and reference male and female body models whose dimensions and mass correspond to those of the International Commission on Radiological Protection (ICRP, 2002) which is about $200 \mathrm{~mm}$ for the trunk and $100 \mathrm{~mm}$ for the head (Pretorius et al., 2009).

The induced current densities in the head, trunk and lower extremities were calculated. The induced current densities for head and trunk were compared to the ICNIRP Basic Restriction of $10 \mathrm{~mA} / \mathrm{m}^{2}$ to determine whether it was exceeded. The dimensions and mass of the head, trunk and lower extremities corresponds to detailed anatomical and reference male and female body models to those of the International Commission on Radiological Protection (ICRP, 2002), which is about $0.2 \mathrm{~m}$ for lower extremities, 0.2 $\mathrm{m}$ for the trunk and $0.1 \mathrm{~m}$ for the head.

Calculation of Magnetic flux densities due to ELF MFs

A magnetic field can be represented as a vector and may be specified in one of two ways: as magnetic flux density $\mathrm{B}$ or as magnetic field strength $\mathrm{H} . \mathrm{B}$ and $\mathrm{H}$ are expressed in teslas (T) and amperes per meter $(\mathrm{A} / \mathrm{m})$, respectively. In a vacuum and with good approximation in air, $\mathrm{B}$ and $\mathrm{H}$ are related by the expression

$$
\mathrm{B}=\mu \mathrm{H}
$$

The constant of proportionality $\mu$ in equation (3) is termed the permeability of free space and has the numerical value $4 \pi \times 10^{-7}$ expressed in henrys per meter $(\mathrm{H} / \mathrm{m})$ (ICNIRP, 2010). 
The resultant field strength for each rack at different heights was derived from the magnetic field intensities using equation (1). This was then used to find the magnetic flux density by multiplying the resultant field strength by the permeability of free space $\mu$.The mean electric field and the magnetic field levels were written as $\bar{x} \pm \mathrm{U}$ in the units of $\mathrm{kV} / \mathrm{m}^{2}$ and $\mu \mathrm{T}$.

\section{Results}

Assessment of Electric field levels in the data centre

Electric field levels for first row

The electric field levels at a distance of 0.671 meters and 0.6, 1.0, 1.5, 1.6 and 1.7 meters of height was measured in front of each rack. Fig. 3 shows the values for the mean electric field values in $\mathrm{kVm}-1$ for each rack on the first row.

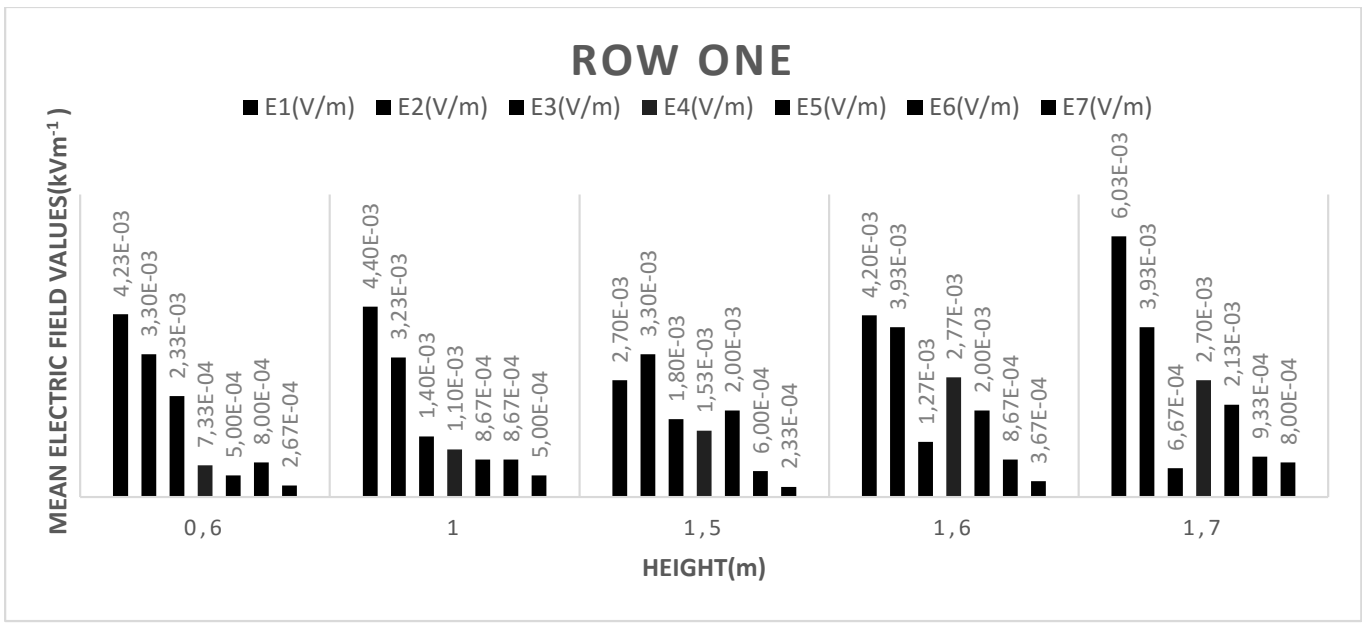

Fig. 3: Values for the mean electric field in $\mathrm{kVm}^{-1}$ for each rack on the first row.

*From left to right for every height: $\mathrm{E} 1(\mathrm{kV} / \mathrm{m})$, $\mathrm{E} 2(\mathrm{kV} / \mathrm{m}), \mathrm{E} 3(\mathrm{kV} / \mathrm{m}), \mathrm{E} 4(\mathrm{kV} / \mathrm{m}), \mathrm{E} 5(\mathrm{kV} / \mathrm{m})$, $\mathrm{E} 6(\mathrm{kV} / \mathrm{m})$ and $\mathrm{E} 7(\mathrm{kV} / \mathrm{m})$ are Electric fields for

\section{Electric field levels for second row}

The electric field levels at a distance of 0.671 meters and $0.6,1.0,1.5,1.6$ and 1.7 meters of height was measured in front of each rack. Fig. first rack, second rack, third rack, fourth rack, fifth rack, sixth rack and seventh rack respectively.

4 shows the values for the mean electric field values in $\mathrm{kVm}^{-1}$ for each rack on the second row. 


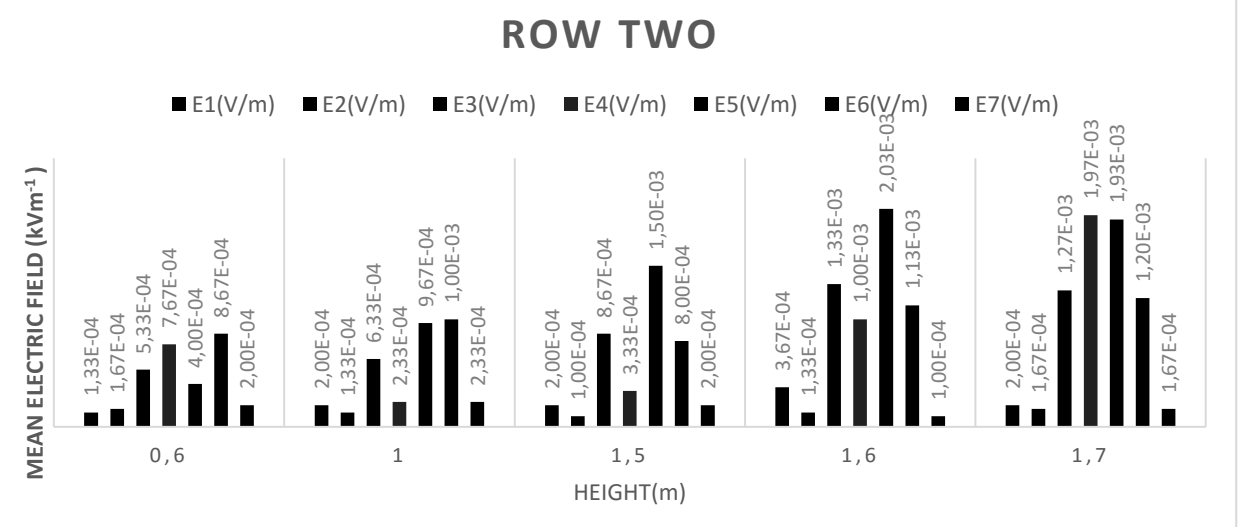

Fig.4. Values for the mean electric field in $\mathrm{kVm}^{-1}$ for each rack on the second row.

*From left to right for every height: $\mathrm{E} 1(\mathrm{kV} / \mathrm{m}), \quad$ The electric field levels at a distance of 0.671 $\mathrm{E} 2(\mathrm{kV} / \mathrm{m}), \mathrm{E} 3(\mathrm{kV} / \mathrm{m}), \mathrm{E} 4(\mathrm{kV} / \mathrm{m}), \mathrm{E} 5(\mathrm{kV} / \mathrm{m})$, $\mathrm{E} 6(\mathrm{kV} / \mathrm{m})$ and $\mathrm{E} 7(\mathrm{kV} / \mathrm{m})$ are Electric fields for firstrack, secondrack, thirdrack, fourthrack, fifth rack, sixth rack and seventh rack respectively. meters and 0.6, 1.0, 1.5, 1.6 and 1.7 meters of height was measured in front of each rack. Fig. 5 shows the values for the mean electric fields in $\mathrm{kVm}^{-1}$ for each rack on the third row.

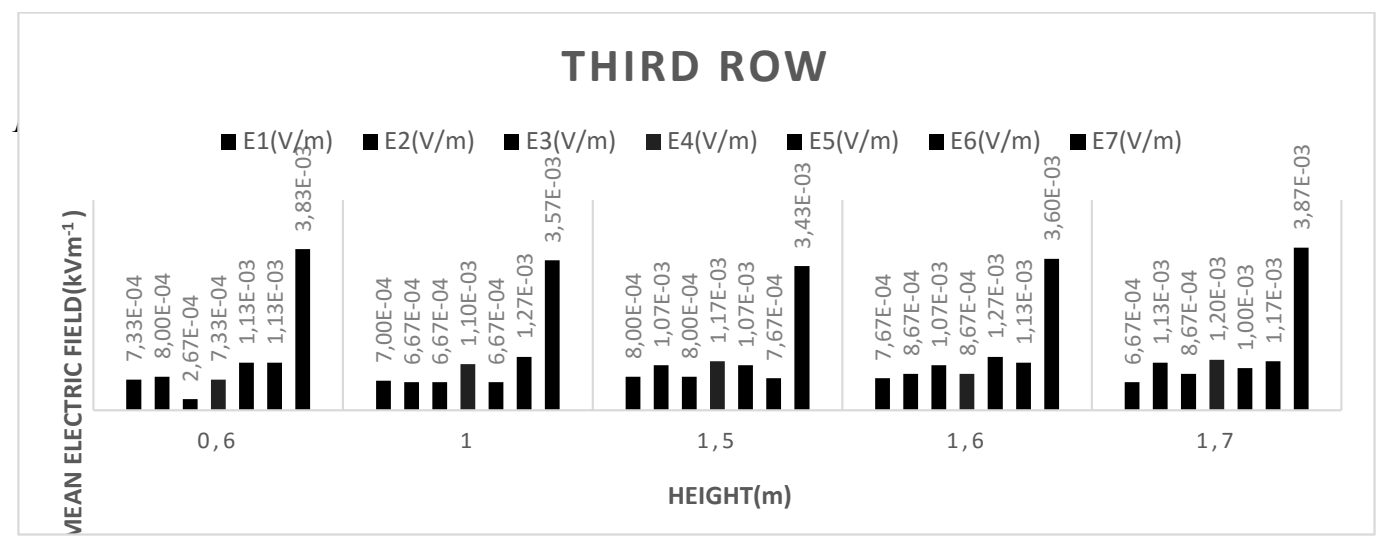

Fig. 5: Values for the mean electric field in $\mathrm{kVm}^{-1}$ for each rack on the third row.

* From left to right for every height: $\mathrm{E} 1(\mathrm{kV} / \mathrm{m})$, $\mathrm{E} 2(\mathrm{kV} / \mathrm{m}), \mathrm{E} 3(\mathrm{kV} / \mathrm{m}), \mathrm{E} 4(\mathrm{kV} / \mathrm{m}), \mathrm{E} 5(\mathrm{kV} / \mathrm{m})$, $\mathrm{E} 6(\mathrm{kV} / \mathrm{m})$ and $\mathrm{E} 7(\mathrm{kV} / \mathrm{m})$ are Electric fields for firstrack, secondrack, thirdrack, fourthrack, fifth rack, sixth rack and seventh rack respectively.
Electric field levels for fourth row

The electric field levels at a distance of 0.671 meters and 0.6, 1.0, 1.5, 1.6 and 1.7 meters of height was measured in front of each rack. Fig. 6 shows the values for the mean electric fields in $\mathrm{kVm}^{-}$for each rack on the fourth row. 


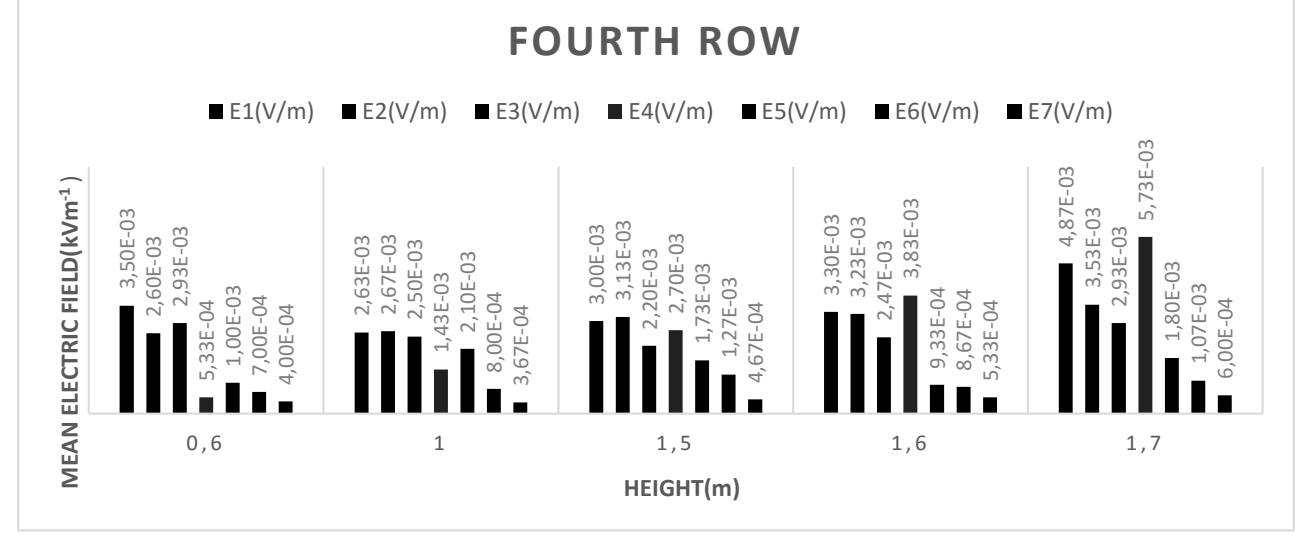

Fig. 6: Values for the mean electric field in $\mathrm{kVm}^{-1}$ for each rack on the fourth row.

* From left to right for every height: $\mathrm{E} 1(\mathrm{kV} / \mathrm{m})$, $\mathrm{E} 2(\mathrm{kV} / \mathrm{m}), \mathrm{E} 3(\mathrm{kV} / \mathrm{m}), \mathrm{E} 4(\mathrm{kV} / \mathrm{m}), \mathrm{E} 5(\mathrm{kV} / \mathrm{m})$, $\mathrm{E} 6(\mathrm{kV} / \mathrm{m})$ and $\mathrm{E} 7(\mathrm{kV} / \mathrm{m})$ are Electric fields for first rack, second rack, third rack, fourth rack, fifth rack, sixth rack and seventh rack respectively.
Assessment of Magnetic flux density using magnetic field levels in the data centre.

Magnetic field levels, Magnetic flux density and Induced current density for first row.The magnetic field levels at a distance of 0.671 meters and 0.6, 1.0, 1.5, 1.6 and 1.7 meters of height was measured in front of each rack. Fig. 7 shows the resultant magnetic field values for the first row in $\mu \mathrm{T}$.

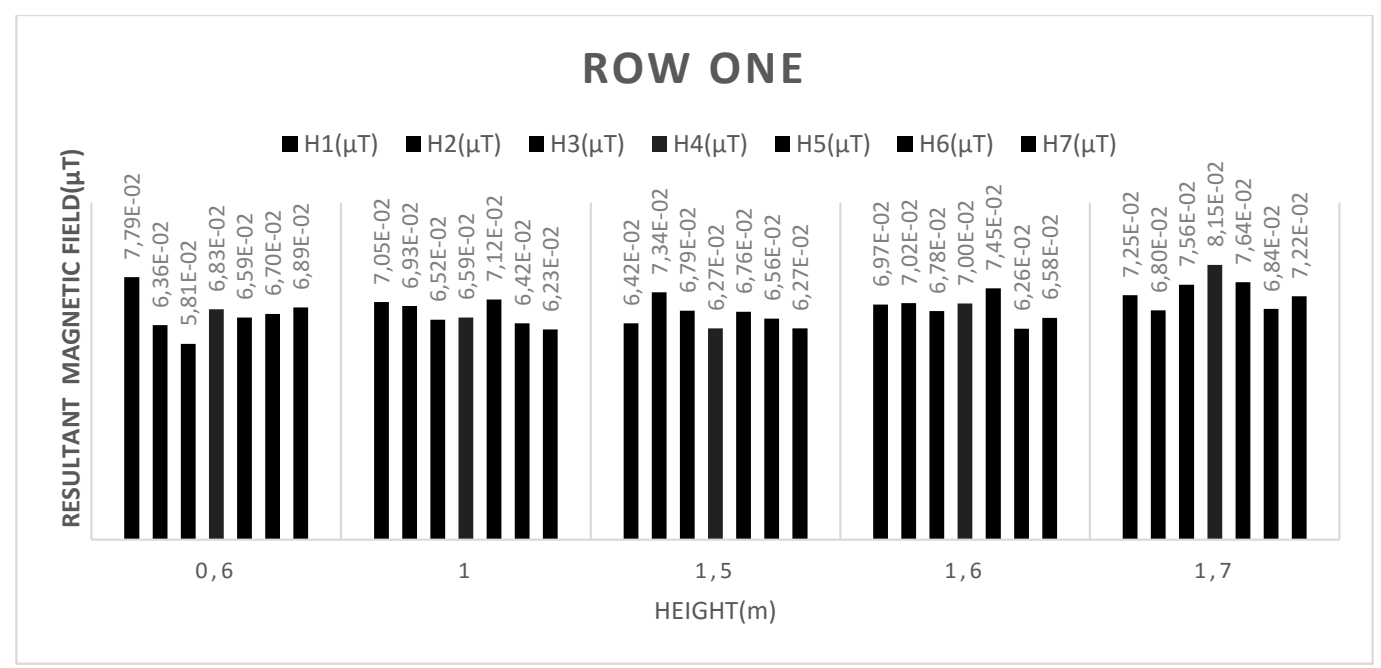

Fig. 7: Resultant magnetic field values for the first row in $\mu \mathrm{T}$. 
*From left to right for every height: $\mathrm{H} 1(\mu \mathrm{T}), \quad$ Fig. 8 shows the comparison of the magnetic $\mathrm{H} 2(\mu \mathrm{T}), \mathrm{H} 3(\mu \mathrm{T}), \mathrm{H} 4(\mu \mathrm{T}), \mathrm{H} 5(\mu \mathrm{T}), \mathrm{H} 6(\mu \mathrm{T})$ flux density of each rack on the first row with and $\mathrm{H} 7(\mu \mathrm{T})$ are resultant magnetic fields for different heights taken.

first rack, second rack, third rack, fourth rack, fifth rack, sixth rack and seventh rack respectively.

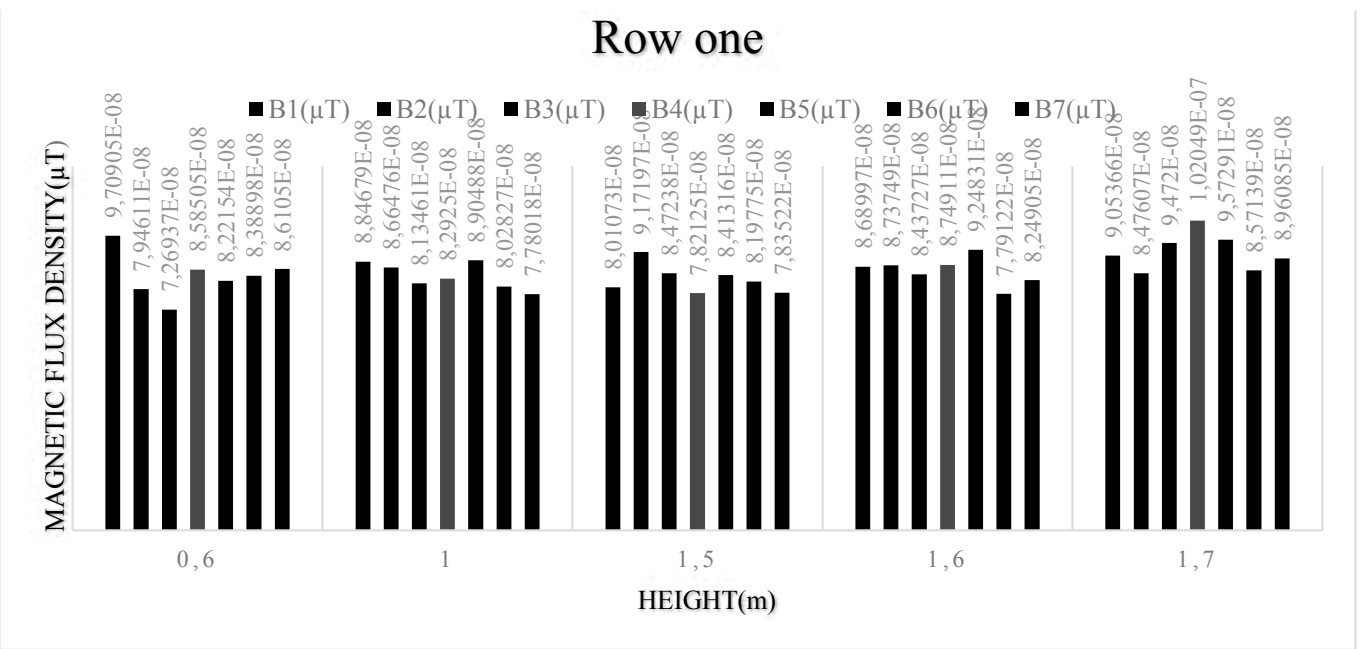

Fig. 8: Magnetic flux densities for the racks at different heights for first row.

*From left to right for every height $\mathrm{B} 1, \mathrm{~B} 2, \mathrm{~B} 3$, $\mathrm{B} 4, \mathrm{~B} 5, \mathrm{~B} 6$ and $\mathrm{B} 7$ are magnetic flux densities for first rack, second rack, third rack, fourth rack, fifth rack, sixth rack and seventh rack respectively.
Fig. 9 shows the comparison of the current density of each rack on the first row with different heights taken.

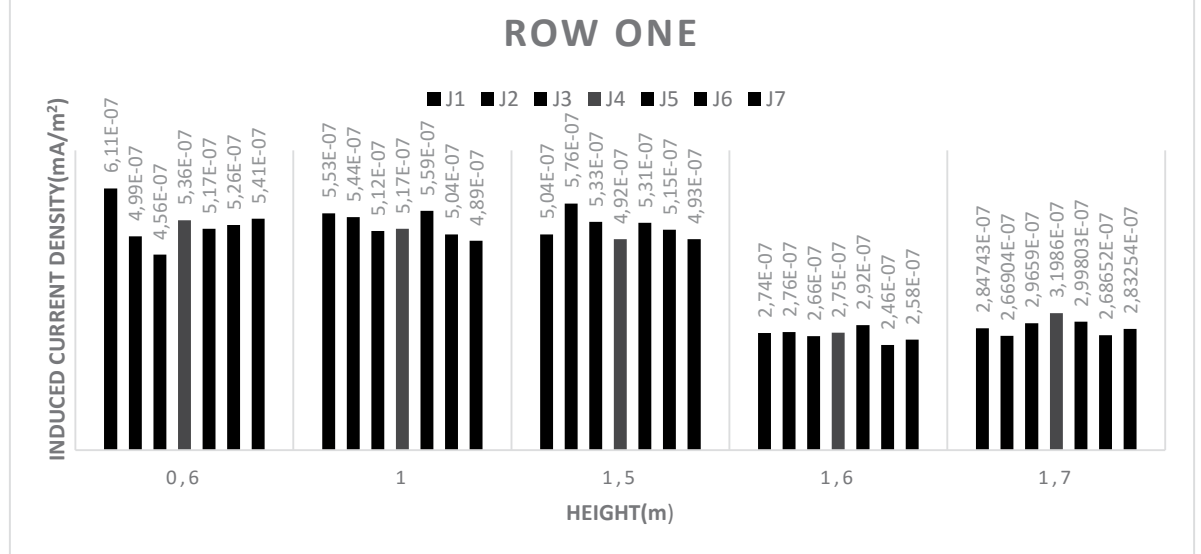

Fig. 9: Induced Current densities for the racks at different heights for first row. 
*From left to right for every height: J1, J2, J3, $\mathrm{J} 4, \mathrm{~J} 5, \mathrm{~J} 6$ and $\mathrm{J} 7$ are induced current densities for first rack, second rack, third rack, fourth rack, fifth rack, sixth rack and seventh rack respectively.
Magnetic field levels and Magnetic flux density for second row.

The magnetic field levels at a distance of 0.671 meters and 0.6, 1.0, 1.5, 1.6 and 1.7 meters of height was measured in front of each rack. Fig. 10 shows the resultant magnetic field values for the second row in $\mu \mathrm{T}$.

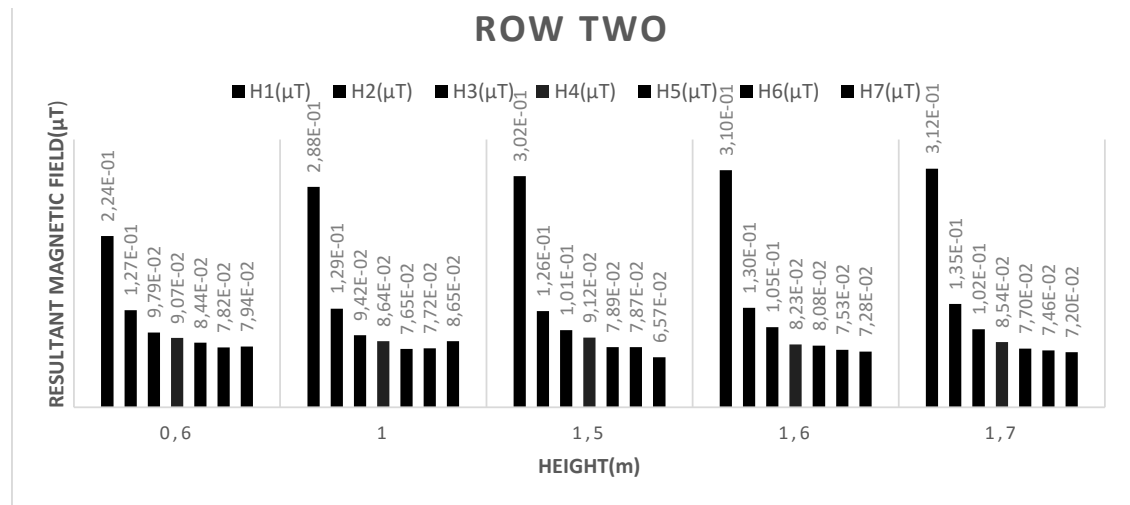

Fig. 10: Resultant magnetic field values for the second row in $\mu \mathrm{T}$.

*From left to right for every height: $\mathrm{H1}(\mu \mathrm{T})$, $\mathrm{H} 2(\mu \mathrm{T}), \mathrm{H} 3(\mu \mathrm{T}), \mathrm{H} 4(\mu \mathrm{T}), \mathrm{H} 5(\mu \mathrm{T}), \mathrm{H} 6(\mu \mathrm{T})$ and $\mathrm{H} 7(\mu \mathrm{T})$ are resultant magnetic fields for first rack, second rack, third rack, fourth rack, fifth rack, sixth rack and seventh rack respectively.
Fig. 11 shows the comparison of the magnetic flux density of each rack on the second row with different heights taken.

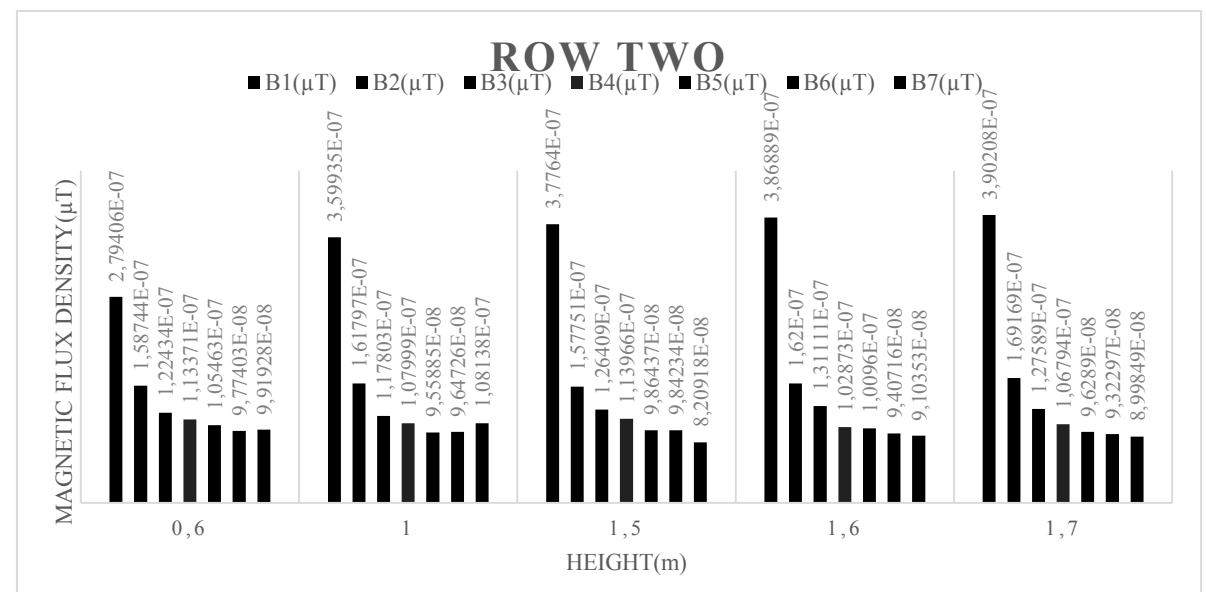

Fig. 11: Magnetic flux densities for the racks at different heights for second row. 
*From left to right for every height: $\mathrm{B} 1, \mathrm{~B} 2$, B3, B4, B5, B6 and B7 are magnetic flux densities for first rack, second rack, third rack, fourth rack, fifth rack, sixth rack and seventh rack respectively.
Fig. 12 shows the comparison of the current density of each rack on the second row with different heights taken

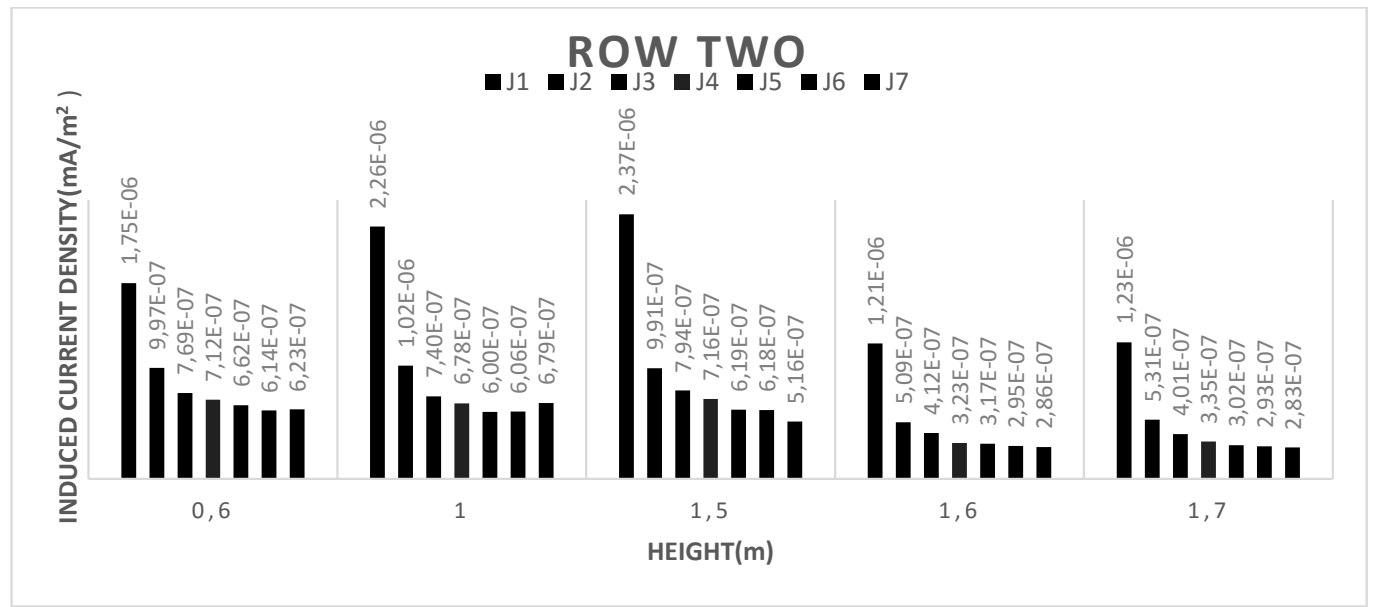

Fig. 12: Induced Current densities for the racks at different heights for second row.

*From left to right for every height: $\mathrm{J} 1, \mathrm{~J} 2, \mathrm{~J} 3$, $\mathrm{J} 4, \mathrm{~J} 5, \mathrm{~J} 6$ and $\mathrm{J} 7$ are induced current densities for first rack, second rack, third rack, fourth rack, fifth rack, sixth rack and seventh rack respectively.
Magnetic field levels and Magnetic flux density for third row.

The magnetic field levels at a distance of 0.671 meters and 0.6, 1.0, 1.5, 1.6 and 1.7 meters of height was measured in front of each rack. Fig. 13 shows the resultant magnetic field values for the third row in $\mu \mathrm{T}$.

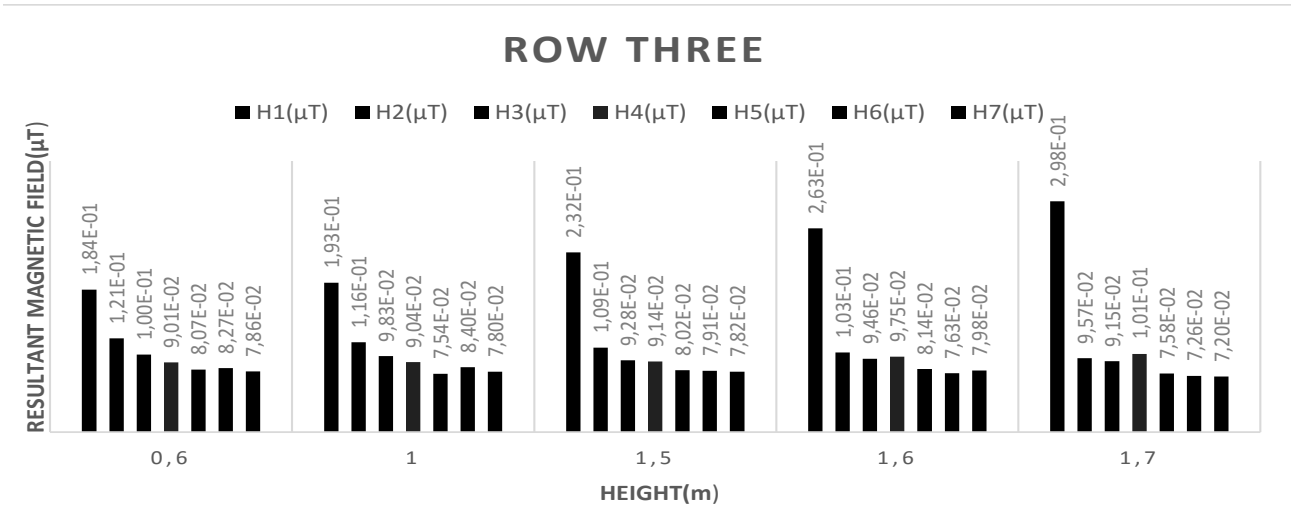

Fig. 13: Resultant magnetic field values for the third row in $\mu \mathrm{T}$. 
*From left to right for every height: $\mathrm{H} 1(\mu \mathrm{T})$, $\mathrm{H} 2(\mu \mathrm{T}), \mathrm{H} 3(\mu \mathrm{T}), \mathrm{H} 4(\mu \mathrm{T}), \mathrm{H} 5(\mu \mathrm{T}), \mathrm{H} 6(\mu \mathrm{T})$ and $\mathrm{H} 7(\mu \mathrm{T})$ are resultant magnetic fields for first rack, second rack, third rack, fourth rack, fifth rack, sixth rack and seventh rack respectively. Fig. 14 shows the comparison of the magnetic flux density of each rack on the third row with different heights taken.

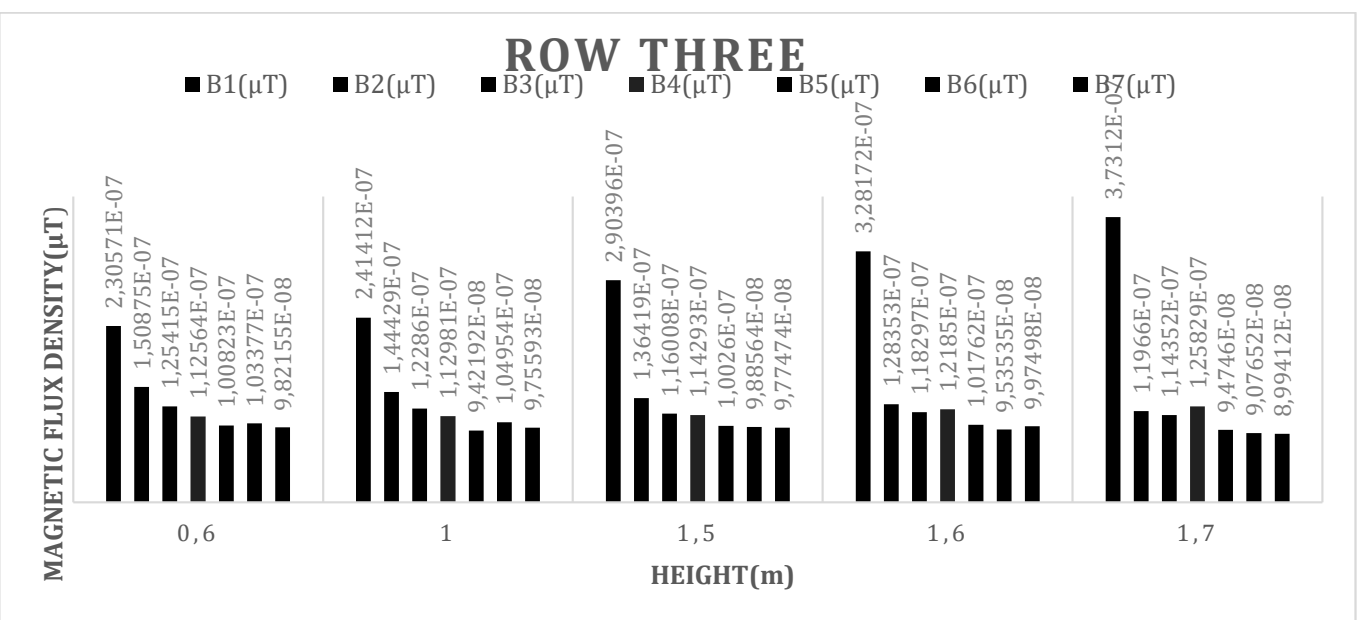

Fig. 14: Magnetic flux densities for the racks at different heights for third row.

* From left to right for every height: B1, B2, B3, B4, B5, B6 and B7 are magnetic flux densities for first rack, second rack, third rack, fourth rack, fifth rack, sixth rack and seventh rack respectively.
Fig. 15 shows the comparison of the current density of each rack on the third row with different heights taken

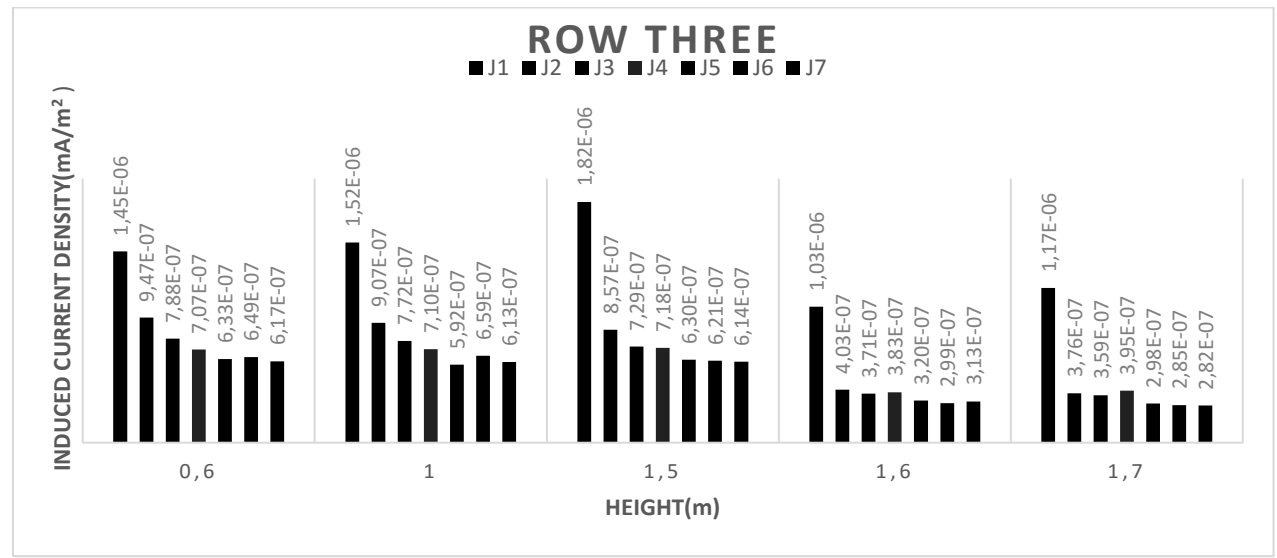

Fig. 15: Induced Current densities for the racks at different heights for third row. 
*From left to right for every height: J1, J2, J3, $\mathrm{J} 4, \mathrm{~J} 5, \mathrm{~J} 6$ and $\mathrm{J} 7$ are induced current densities for first rack, second rack, third rack, fourth rack, fifth rack, sixth rack and seventh rack respectively.
Magnetic field levels and Magnetic flux density for fourth row.

The magnetic field levels at a distance of 0.671 meters and $0.6,1.0,1.5,1.6$ and 1.7 meters of height was measured in front of each rack. Fig. 16 shows the resultant magnetic field values for the fourth row in $\mu \mathrm{T}$.

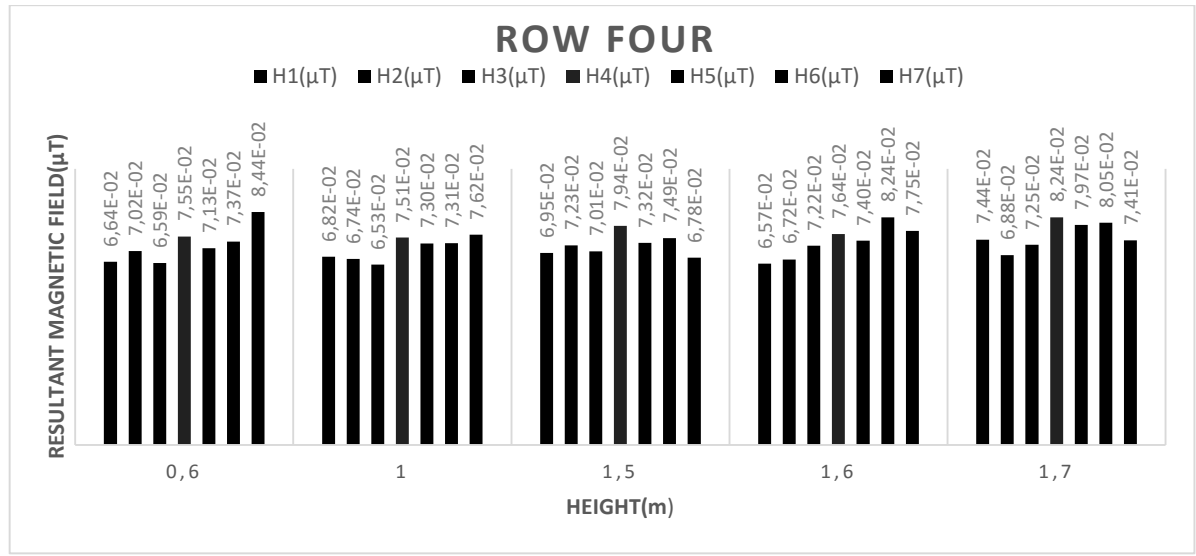

Fig. 16: Resultant magnetic field values for the fourth row in $\mu \mathrm{T}$.

* From left to right for every height: $\mathrm{H} 1(\mu \mathrm{T})$, $\mathrm{H} 2(\mu \mathrm{T}), \mathrm{H} 3(\mu \mathrm{T}), \mathrm{H} 4(\mu \mathrm{T}), \mathrm{H} 5(\mu \mathrm{T}), \mathrm{H} 6(\mu \mathrm{T})$ and $\mathrm{H} 7(\mu \mathrm{T})$ are resultant magnetic fields for first rack, second rack, third rack, fourth rack, fifth rack, sixth rack and seventh rack respectively.
Fig. 17 shows the comparison of the magnetic flux density of each rack on the fourth row with different heights taken.

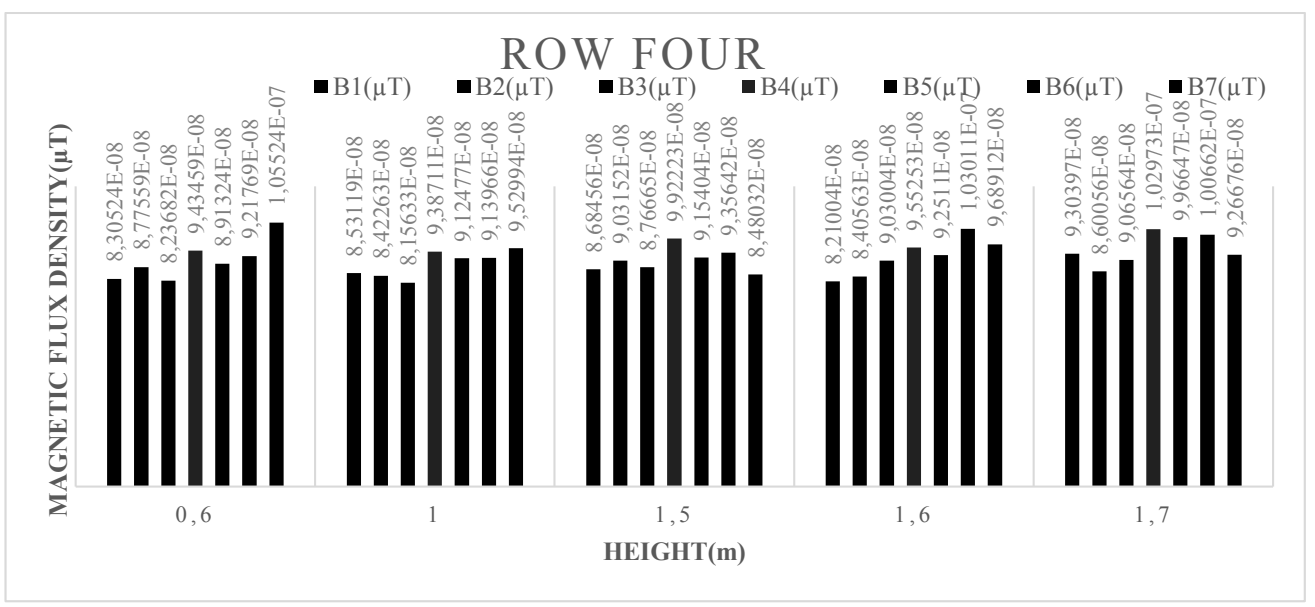

Fig. 17: Magnetic flux densities for the racks at different heights for fourth row. 
*From left to right for every height: B1, B2, B3, B4, B5, B6 and B7 are magnetic flux densities for first rack, second rack, third rack, fourth rack, fifth rack, sixth rack and seventh rack respectively. Fig. 18 shows the comparison of the current density of each rack on the fourth row with different heights taken

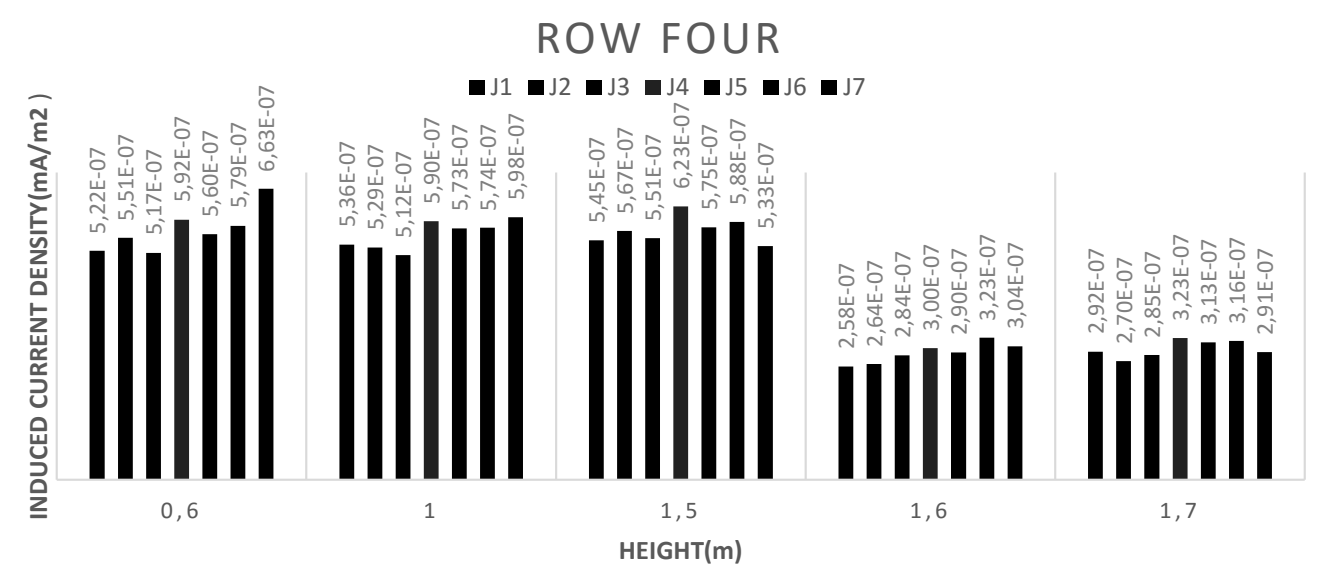

Fig. 18: Induced Current densities for the racks at different heights for fourth row.

* From left to right for every height: $\mathrm{J} 1, \mathrm{~J} 2, \mathrm{~J} 3, \mathrm{~J} 4$, $\mathrm{J} 5, \mathrm{~J} 6$ and $\mathrm{J} 7$ are induced current densities for first rack, second rack, third rack, fourth rack, fifth rack, sixth rack and seventh rack respectively.

\section{Discussion}

Exposure of workers in the data centre to ELF electric and magnetic fields was assessed by ME 3851A Digital Electrostress Analyzer. The electric and magnetic field values were used to compute for the mean electric field, resultant magnetic field, magnetic flux density and the induced current density.

For the results for the mean electric field values (Fig. 3 to 6 ), a worker standing at row one in the data centre will experience the maximum mean electric field $(6.03 \mathrm{E}-03 \pm 7.54 \mathrm{E}-$ $\left.04 \mathrm{kVm}^{-1}\right)$ around the head level at 1.7 meters height (first rack).
Also a relationship can be seen between the resultant magnetic field (Fig. 7, 10, 13 and 16) and the magnetic flux density (Fig. 8, 11, 14 and 17). A high resultant magnetic field will result in a high magnetic flux density and a low resultant magnetic field will also result in a low magnetic flux density. The position and height for the maximum resultant magnetic field was the same position and height for the maximum magnetic flux density which was at row two (first rack) 1.7 meters height. The maximum resultant magnetic field was $3.12 \mathrm{E}-01 \pm 8.77 \mathrm{E}-$ $03 \mu \mathrm{T}$ and the maximum magnetic flux density was $3.90 \mathrm{E}-07 \pm 8.77 \mathrm{E}-03 \mu \mathrm{T}$. The high increase as compared to the other racks was as a result of the first rack being close to a fire panel and an electrical distribution board.

Comparing the results for induced current densities (Fig. 9, 12, 15 and 18), the maximum value was $2.37 \mathrm{E}-06 \pm 1.50 \mathrm{E}-02 \mathrm{~mA} / \mathrm{m}^{2}$ for row 
two (first rack 1.5 meters height). A worker in the data centre will have a maximum induced current density around the trunk region.

\section{Results Compared to International Standards} The International Commission on Non-Ionizing Radiation Protection (ICNIRP) guidelines are the most accepted guidelines for non-ionizing radiation. They are endorsed by the World Health Organization (WHO), for the International Union for Telecommunication (ITU) and for more than 30 countries all over the world including administrations of health, telecommunications, environment and others.

The International Commission on Non-Ionizing Radiation Protection (ICNIRP) has set-up guidelines for limiting exposure to time varying electric and magnetic fields (1 Hz-100 kHz) published in: health physics 99(6):818-836; 2010. Table 1 shows the summary of the ICNIRP (1998) Exposure Guidelines.

\section{TABLE 1}

Basic restrictions and guidelines for occupational exposure to $50 \mathrm{~Hz}$ ELF electric and magnetic fields.

\begin{tabular}{cccc}
\hline EXPOSURE & BASIC & \multicolumn{2}{c}{ REFERENCE LEVEL } \\
CHARACTERISTICS & RESTRICTIONS & & \\
\hline & & & \\
& INDUCED & ELECTRIC FIELD & MAGNETIC \\
& CURRENT & STRENGTH & FLUX DENSITY \\
& DENSITY $\left(\mathrm{mA} / \mathrm{m}^{2}\right)$ & $(\mathrm{kV} / \mathrm{m})$ & $(\mu \mathrm{T})$ \\
\hline OCCUPATIONAL & 10 & 10 & 500
\end{tabular}

*Source: ICNIRP guidelines (1998).

The maximum electric field measured was $6.03 \mathrm{E}-03 \pm 7.54 \mathrm{E}-04 \mathrm{kVm}^{-}{ }^{1}$. The maximum magnetic flux density expected was $3.9 \mathrm{E}-07 \pm$ $8.77 \mathrm{E}-03 \mu \mathrm{T}$. The maximum induced current densities expected in the head was $1.23 \mathrm{E}-06$ $\pm 8.77 \mathrm{E}-03 \mathrm{~mA} / \mathrm{m}^{2}$ for row two (first rack 1.7 meters height) and trunk of the workers was $2.37 \mathrm{E}-06 \pm 1.50 \mathrm{E}-02 \mathrm{~mA} / \mathrm{m}^{2}$ for row two (first rack 1.5 meters height). These are within the ICNIRP Reference Level and Basic Restriction.

\section{Conclusion}

The maximum electric field measured was $6.03 \mathrm{E}-03 \pm 7.54 \mathrm{E}-04 \mathrm{kVm}^{-}{ }^{1}$. The maximum magnetic flux density expected was $3.9 \mathrm{E}-07 \pm$ 8.77E-03 $\mu \mathrm{T}$. The maximum induced current densities expected in the head was $1.23 \mathrm{E}-06$ $\pm 8.77 \mathrm{E}-03 \mathrm{~mA} / \mathrm{m}^{2}$ for row two (first rack 1.7 meters height) and trunk of the workers was $2.37 \mathrm{E}-06 \pm 1.50 \mathrm{E}-02 \mathrm{~mA} / \mathrm{m}^{2}$ spending less time in the data centre and also by keeping their distances from hot spots in the data centre. They can also run shifts in the data centre. Measurement of electric and magnetic field levels for other data centres for Telecommunication Network Operators in Ghana should be carried out. The ELF electric and magnetic fields should be assessed for workers in data centres nation-wide in order to assess their exposure. Further work should be done in relation to the time spent in the data centre.

\section{Recommendations}

Policy makers such as the National Communication Authority (NCA) and the Ministry of Communications should develop and adopt limits for exposure to extremely low frequency electromagnetic fields locally for data centres and other electrical equipment.

Telecommunication Network Operators should appoint radiation protection officers to check the levels of electric and magnetic fields in their data centres periodically. Also when building or expanding their data centres, radiation protection officers should be consulted in the designing stage of the data centre and to help identify hot spots (areas in the data centres 
which have high electric and magnetic fields) in the data centre after completion.

Workers in the data centre can reduce their exposure by spending less time in the data centre and also by keeping their distances from hot spots in the data centre. They can also run shifts in the data centre.

\section{References}

Glanz, J. (2012) "Power, Pollution and the Internet". The New York Times. Retrieved 25th August, 2012.

Habash, R. W. Y. (2001) Electromagnetic fields and Radiation: Human bioeffects and safety. New York: Marcel Dekker.

ICNIRP (1998) Guidelines for Limiting Exposure to Time-Varying Electric, Magnetic and Electromagnetic Fields (up to $300 \mathrm{GHz}$ ), Health Phys. 74 (4), 494 - 522.
ICNIRP (2010) Guidelines for Limiting Exposure to Time-Varying Electric and Magnetic Fields (1 $\mathrm{Hz}$ to $100 \mathrm{kHz}$ ): $818-819$.

ICRP 89 (2002) Basic Anatomical and Physiological Data for Use in Radiological Protection: Reference Values: 63 - 66 .

Kwan-Hoong NG. (2003), Non-Ionizing RadiationsSources, Biological Effects, Emissions and Exposures, Department of Radiology, University of Malaya.

NRPB (2001) ELF Electromagnetic Fields and the Risk of Cancer, Report of an Advisory Group on Non-ionizing Radiation (Doc NRPB 12), Chilton, UK.

Pretorius, P. H., Luhlanga, P. \& Bhulose, P. T. (2009) Magnetic Field Exposure of Live Line Workers on High Power Transfer $765 \mathrm{kV}$ and $400 \mathrm{kV}$ Power Lines, ISBN 978- 0-620- 44584-9:1-2.

Received 7 May 18; revised 8 Jan 19. 